
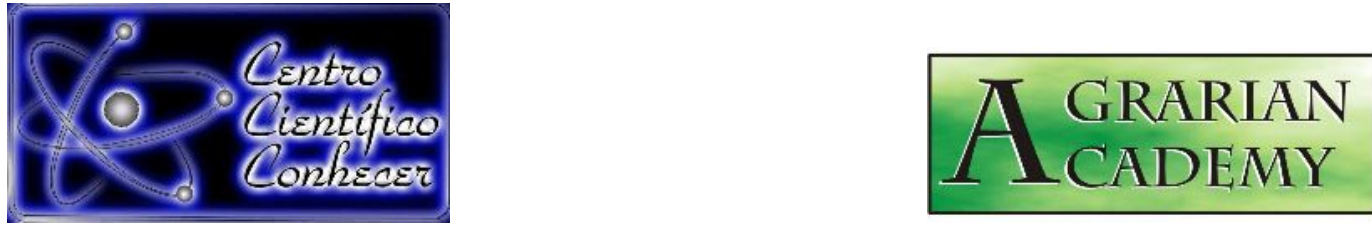

\title{
VARIAÇÃO DA COMPOSIÇÃO, QUALIDADE, PRODUÇÃO E PREÇO DO LITRO DO LEITE NAS ESTAÇÕES DO ANO EM UMA PROPRIEDADE LEITEIRA NO NORTE DO ESTADO DO RIO GRANDE DO SUL- BRASIL
}

\author{
Karen Dal Magro Frigeri ${ }^{1}$, Ketlin Dal Magro Frigeri², Thais Paula Santin ${ }^{3}$, Naiane \\ Zondan Kalles ${ }^{4}$, Alessandra Agostini ${ }^{5}$.
}

${ }^{1}$ Acadêmica do curso de Zootecnia, Universidade Federal de Santa Maria (UFSM), (karen.frigeri@gmail.com), Palmeira das Missões -RS/Br.

${ }^{2}$ Acadêmica do curso de Agronomia, Universidade Federal da Fronteira Sul (UFFS), Chapecó - SC/Br.

${ }^{3}$ Acadêmica do curso de Zootecnia, Universidade Federal de Santa Maria (UFSM), Palmeira das Missões -RS/Br.

${ }^{4}$ Acadêmica do curso de Agronomia, Universidade Federal da Fronteira Sul (UFFS), Chapecó - SC/Br.

${ }^{5}$ Acadêmica do curso de Zootecnia, Universidade Federal de Santa Maria (UFSM), Palmeira das Missões - $\mathrm{RS} / \mathrm{Br}$.

\section{Recebido em: 01/04/2020 - Aprovado em: 10/06/2020 - Publicado em: 30/07/2020 DOI: 10.18677/Agrarian_Academy_2020a7}

\begin{abstract}
RESUMO
As transformações nas propriedades do leite afetam diretamente a matéria prima in natura influenciando principalmente em sua qualidade, que é considerado um padrão de extrema importância em qualquer sistema de produção. Sendo a qualidade definida por parâmetros físico-químicos e microbiológicos, como gordura, proteínas, sólidos totais, contagem de células somáticas (CCS) e contagem padrão em placas (CPP), torna-se evidente que alterações climáticas durante as estações do ano, principalmente no Sul do Brasil, que apresenta as quatro estações bem definidas, podem causar estresse no rebanho contribuindo na diminuição da produção de leite, nos parâmetros de qualidade e consequentemente no preço final pago ao produtor. Desta maneira, objetivou-se avaliar a variação da composição, qualidade, produção e preço do litro do leite nas estações do ano. Assim sendo, utilizou-se amostras coletadas durante 72 meses no período de janeiro de 2013 a dezembro de 2018. Os dados analisados referentes a composição do leite foram a gordura, proteína, lactose e sólidos totais, já a respeito da qualidade foram analisados a CCS e a CPP, além da produção e o preço pago pelo litro. 0 delineamento foi inteiramente casualizado com medidas repetidas no tempo, os dados foram analisados por meio de análise de variância, sendo as médias comparadas pelo teste Scoot Knott, com nível de significância de 5\%. As estações do ano apresentaram efeito significativo $(P<0,05)$ sobre os teores de gordura, proteína, lactose, sólidos totais e produção média, mas não influenciaram na qualidade e preço pago pelo litro do leite.
\end{abstract}

PALAVRAS-CHAVE: CCS, época do ano, gordura, lactose, proteína 


\title{
VARIATION OF COMPOSITION, QUALITY, PRODUCTION AND PRICE OF MILK LITER IN SEASONS OF THE YEAR IN A MILK PROPERTY IN THE NORTHERN STATE OF RIO GRANDE DO SUL- BRAZIL
}

\begin{abstract}
The changes in the properties of milk directly affect the raw material in natura, mainly influencing its quality, which is considered an extremely important standard in any production system. Since the quality is defined by physical-chemical and microbiological parameters, such as fat, proteins, total solids, somatic cell count (SCC) and standard plate count (PCP), it becomes evident that climate changes during the seasons, especially in the south of Brazil, which has the four well-defined seasons, they can cause stress in the herd, contributing to the reduction of milk production, quality parameters and, consequently, the final price paid to the producer. Thus, the objective was to evaluate the variation in composition, quality, production and price of the liter of milk for the seasons. Therefore, samples collected during 72 months from January 2013 to December 2018 were used. The data analyzed for the composition of milk were fat, protein, lactose and total solids, while the quality was analyzed by SCC and the PCP, in addition to the production and the price paid per liter. The design was completely randomized with repeated measures over time, the data were analyzed using analysis of variance, and the means were compared using the Scoot Knott test, with a significance level of $5 \%$. The seasons showed a significant effect $(P<0.05)$ on the levels of fat, protein, lactose, total solids and average production, but did not influence the quality and price paid for the liter of milk.
\end{abstract}

KEYWORDS: season of year, SCC, fat, lactose, protein

\section{INTRODUÇÃO}

Entre os diversos segmentos econômicos, a cadeia produtiva do leite e seus derivados ocupam uma posição de destaque na economia brasileira (CARVALHO et al., 2018). Desta maneira, a determinação da composição e da qualidade do leite é de extrema importância para a indústria láctea, a qual visa o maior rendimento industrial, para tanto, as mesmas devem estar de acordo com as Instruções Normativas vigentes no país. Os parâmetros de qualidade da matéria prima in natura são cada vez mais utilizados para determinar falhas de manejo nas fazendas leiteiras (CARVALHO et al., 2018).

Segundo Lima (2004) adquirir leite de qualidade adequada ao consumo em termos nutricionais e de segurança alimentar depende de processos controlados em todos os estágios de produção, desde a formação do rebanho até a entrega do leite para as empresas responsáveis. A qualidade do leite deve ser considerada em todos os modelos de sistemas de produção, pois as alterações que ocorrem no leite afetarão diretamente a matéria prima in natura; essas alterações podem ocorrer durante processos como a pasteurização e UHT (Ultra High Temperature), na produção de leite e de seus derivados, sendo uma questão de saúde pública (JAMAS et al., 2018).

Sendo assim, a composição do leite permite monitorar o rebanho leiteiro a partir da gordura, proteína, lactose, extrato seco total (EST), extrato seco desengordurado (ESD), contagem de células somáticas (CCS) e contagem padrão em placas (CPP), permitindo assim, analisar as falhas na nutrição, no manejo e correção dos mesmos pelo produtor (DIAS et al., 2017). Além disso, a CCS e CPP são considerados bons indicadores internacionais para avaliar a qualidade do leite 
(PEIXOTO et al., 2016), rendimento industrial e determinação da segurança alimentar do produto (LAMPUGNANI et al., 2018).

Por conseguinte, transformações e peculiaridades de cada sistema tornam a atividade uma das mais complexas do setor agropecuário (NORONHA; LIMA JUNIOR, 2005). O Brasil é o quarto maior produtor de leite do mundo (EMBRAPA, 2018), com a Região Sul no ano de 2018 liderando a produção nacional, responsável por $40,1 \%$ da produção (IBGE, 2018). Nos últimos 50 anos a produção de leite efetiva cresceu 673\%, representando aumento de 30 milhões de litros de leite, isto decorreu em virtude do crescimento da produtividade animal (VILELA et al., 2017).

Portanto, objetivou-se analisar a variação da composição, qualidade, produção e preço do litro do leite nas diferentes estações do ano em um sistema de semiconfinamento de uma propriedade na região Norte do Estado do Rio Grande do Sul.

\section{MATERIAL E MÉTODOS}

A elaboração do banco de dados para a realização da pesquisa deu-se pelos registros coletados e fornecidos por uma propriedade leiteira ao Norte do Estado do Rio Grande do Sul. O clima predominante da região é subtropical úmido (Cfa), com temperatura média anual de $22^{\circ} \mathrm{C}$, com verões quentes e chuvas bem distribuídas durante 0 ano (ALVARES et al., 2013). A propriedade está situada a latitude: $27^{\circ} 42^{\prime}$ 31" sul, longitude: $52^{\circ} 55^{\prime} 50^{\prime \prime}$ oeste e a 506 metros de altitude.

Os dados referentes a composição e qualidade do leite foram coletados uma vez ao mês, no tanque de resfriamento da propriedade, durante os meses de janeiro de 2013 a dezembro de 2018, tendo um total de 72 períodos de avaliação. A coleta foi realizada por um representante da empresa na qual o produtor entrega seu produto. As análises de composição e qualidade do leite foram exercidas pelo Laboratório de Serviços de Rebanhos Leiteiros (SARLE) da Universidade de Passo Fundo (UPF), sendo o mesmo credenciado pelo Ministério da Agricultura, Pecuária e Abastecimento (MAPA).

O rebanho leiteiro é composto por vacas da raça Holandês e Jersey, com diferentes idades e fases de lactação. Tendo em vista que a propriedade tem um sistema de produção baseado no uso de pastagens, com suplementação de concentrado, forragens conservadas, sendo: silagem de milho (Zea mays. L) e feno de Jiggs (Cynodon spp) e, adição de aditivos para prevenção de mastites, sequestrantes de micotoxinas e bicarbonato de sódio durante o ano todo.

Durante os meses de novembro a abril, os animais ficam em pastagens perenes de grama Jiggs (Cynodon spp) e Tifton-85 (Cynodon spp.), além de pastagens anuais de verão, sendo: milheto (Pennisetum americanum L.) e sorgo (Sorghum bicolor). De maio a setembro os animais ficam em pastagens anuais de inverno, sendo constituídas por aveia branca (Avena sativa L.) e azevém (Lolium multiflorum).

A sala de ordenha é do tipo espinha de peixe, as vacas eram ordenhadas duas vezes ao dia, sendo que pela manhã a ordenha é realizada às sete horas e a tarde às 17 horas e 30 minutos. $O$ tanque de resfriamento é do modelo 4 ordenhas com capacidade de armazenamento de 750 litros.

Em relação a higienização dos tetos, foi distinta durante os anos analisados. De 2012 a 2017, utilizava-se apenas água potável para a higienização dos tetos, e o teste de Califórnia Mastitis Test (CMT) era realizado em casos suspeitos de mastite no rebanho. A partir de 2016, foi incluído no manejo de ordenha o pós-dipping a 
base de iodo para higienização dos tetos. Somente a partir de 2018 passou-se a utilizar o pré-dipping diariamente, e após, os tetos eram secos com papel toalha, em seguida retirava-se os três primeiros jatos de leite, em caneco de fundo preto para detecção de mastite clínica.

A higienização da ordenha era realizada utilizando-se água fria durante o período de circulação de 10 minutos, contribuindo assim para a retirada do resíduo da matéria-prima in natura. Para remoção de gordura e proteína utilizava-se $100 \mathrm{~mL}$ de detergente alcalino clorado diluídos em 40 litros de água, com temperatura média de $70^{\circ} \mathrm{C}$, durante o tempo de circulação de 10 minutos, enquanto que para remoção de minerais, eram diluídos $100 \mathrm{~mL}$ de detergente ácido em 40 litros de água, com temperatura média de $45^{\circ} \mathrm{C}$, durante o tempo de circulação de 10 minutos. Para a higienização do tanque de resfriamento utilizava-se detergente alcalino com água fria.

Os dados analisados referentes a composição do leite foram a gordura, proteína, lactose e extrato seco total (EST), (Tabela 1), os quais foram determinados por espectrofotometria com radiação infravermelha utilizando equipamento Bentley ${ }^{\circledR}$ 2000 (Bentley Instruments, Chaska, MN, EUA); já a respeito da qualidade foram analisados: contagem de células somáticas (CCS) e contagem padrão em placas (CPP), (Tabela 1), determinados por citometria de fluxo utilizando equipamento Bactocount® IBC (Bentley Instruments, Chaska, MN, EUA). Além disso, foram analisadas a produção e o preço pago pelo litro, em um sistema semiconfinado. Tendo um total de análise de 72 amostras.

TABELA 1- Estatística descritiva da produção, preço, composição do leite, contagem de células somáticas e contagem padrão em placas.

\begin{tabular}{lccccc}
\hline Variável & $\mathrm{N}$ & Mínimo & Máximo & Média & $\mathrm{DP}$ \\
\hline Preço (R\$/L) & 72 & 0,73 & 1,63 & 1,09 & 0,21 \\
Produção total (L) & 72 & 4,815 & 12,975 & 9073,40 & 1610,27 \\
Gordura (\%) & 72 & 2 & 4,5 & 3,92 & 0,47 \\
Proteína (\%) & 72 & 3,01 & 3,9 & 3,40 & 0,20 \\
Lactose (\%) & 72 & 4,14 & 4,78 & 4,38 & 0,11 \\
EST (\%) & 72 & 10,1 & 15,51 & 12,57 & 0,80 \\
CCS (1000* cel/mL) & 72 & 44,000 & 1533,000 & 592,319 & 346,225 \\
CPP (1000 *UFC/mL) & 72 & 10,000 & 750,000 & 335,153 & 534,686 \\
\hline
\end{tabular}

$\mathrm{N}$ : Número de observações; DP: Desvio padrão; EST: extrato seco total; CCS: contagem de células somáticas; CPP: contagem padrão em placas.

As estações do ano foram divididas em: verão (janeiro, fevereiro e março), outono (abril, maio e junho), inverno (julho, agosto e setembro) e primavera (outubro, novembro e dezembro). Para elaboração do BD das temperaturas, foram coletados registro do Instituto Nacional de Meteorologia (INMET) da região Norte do estado do Rio Grande do Sul, na cidade de Passo Fundo, desta forma, foram computados temperatura máxima, mínima e média sendo as mesmas analisadas por estação e por ano (Tabela 2). 
TABELA 2- Temperatura máxima, mínima e média das estações entre os anos de 2013, 2014, 2015, 2016, 2017 e 2018, para a Região Norte do Estado do Rio Grande do Sul, Brasil.

\begin{tabular}{|c|c|c|c|}
\hline \multicolumn{4}{|c|}{ Temperatura } \\
\hline & Máxima & Mínima & Média \\
\hline Estação do ano & \multicolumn{2}{|c|}{2013} & \\
\hline Verão & 28,61 & 15,78 & 20,35 \\
\hline Outono & 25,09 & 11,04 & 15,24 \\
\hline Inverno & 19,14 & 9,19 & 13,06 \\
\hline Primavera & 27,26 & 15,42 & 21,07 \\
\hline \multicolumn{4}{|c|}{2014} \\
\hline Verão & 28,47 & 17,43 & 21,98 \\
\hline Outono & 20,66 & 11,92 & 15,37 \\
\hline Inverno & 21 & 11,02 & 15,04 \\
\hline Primavera & 26,99 & 17,42 & 21,74 \\
\hline \multicolumn{4}{|c|}{2015} \\
\hline $\begin{array}{l}\text { Verão } \\
\end{array}$ & 27,73 & 17,42 & 21,74 \\
\hline Outono & 21,28 & 11,92 & 18,57 \\
\hline Inverno & 21,50 & 13,14 & 15,77 \\
\hline Primavera & 25,32 & 15,31 & 19,79 \\
\hline \multicolumn{4}{|c|}{2016} \\
\hline Verão & 27,60 & 17,85 & 21,99 \\
\hline Outono & 20,01 & 16,66 & 14,47 \\
\hline Inverno & 19,75 & 9,21 & 13,67 \\
\hline Primavera & 26,32 & 14,42 & 19,75 \\
\hline \multicolumn{4}{|c|}{2017} \\
\hline Verão & 27,54 & 17,45 & 21,73 \\
\hline Outono & 19,92 & 11,02 & 18,51 \\
\hline Inverno & 22,84 & 11,19 & 16,01 \\
\hline Primavera & 26,37 & 14,24 & 19,81 \\
\hline \multicolumn{4}{|c|}{2018} \\
\hline Verão & 27,31 & 16,33 & 21,18 \\
\hline Outono & 21,87 & 11,49 & 21,18 \\
\hline Inverno & 19,87 & 9,54 & 14,00 \\
\hline Primavera & 26,51 & 14,78 & 20,20 \\
\hline
\end{tabular}

Fonte: Instituto Nacional de Meteorologia (INMET).

O delineamento experimental adotado foi o inteiramente casualizado com medidas repetidas no tempo. O banco de dados totalizou 72 repetições. Os dados foram analisados por meio de análise de variância, sendo as médias comparadas pelo teste Scoot Knott, com nível de significância de 5\%, utilizando-se o programa computacional Sistema para Análise de Variância - SISVAR (FERREIRA, 2014).

\section{RESULTADOS E DISCUSSÃO}

O menor teor de gordura (Tabela 3) encontrado no outono pode ser decorrente da menor produção de leite encontrada na mesma estação (Tabela 4), concentrando o teor de gordura no leite, visto que, as pastagens tropicais (Cynodon dactylon, Cynodon spp, Pennisetum americanum L, Sorghum bicolor) possuem baixa qualidade nutricional em comparação às pastagens temperadas (Avena sativa 
L, Lolium multiflorum). Resultados semelhantes foram relatados por Milani et al. (2016). Além disso, no outono as espécies forrageiras tropicais estão no final do ciclo produtivo, apresentando menores teores de carboidratos não fibrosos e maiores teores de fibra em detergente neutro, evidenciando assim, o aumento no teor de gordura no leite (FÉRRER et al., 2018).

Quanto ao teor de proteína, os menores valores foram observados no verão e na primavera (Tabela 3); visto que, o verão é caracterizado por apresentar os maiores índices de temperatura entre as estações, o que resulta em estresse térmico sobre os animais, influenciando diretamente no consumo de matéria seca, além de interferir na qualidade das forragens (DIAS et al., 2015), ainda, o estresse térmico limita a quantidade de aminoácidos transportados pela corrente sanguínea e posteriormente transferidos para a glândula mamária, interferindo na síntese de proteína no leite (HAYGERT-VELHO et al., 2018), além disso, o verão e a primavera obtiveram as maiores produções de leite entre as estações (Tabela 4); diluindo o teor de proteína no leite. Os maiores teores de proteína foram encontrados no outono e no inverno (Tabela 3).

A lactose é o principal carboidrato do leite, seu teor médio varia de 4,4 a $4,6 \%$, a mesma pode variar de acordo com a raça, mastite e estágio de lactação. A lactose é sintetizada principalmente a partir de glicose. O menor teor de lactose foi encontrado no outono (Tabela 3); considerando que a lactose é o principal determinante da produção de leite, pois possui um papel fundamental no controle da pressão osmótica da glândula mamária (SANTOS; FONSECA, 2019), esse resultado explica o menor volume de leite produzido no outono (Tabela 4). A elevação do conteúdo de sólidos totais no outono e no inverno (Tabela 3); deu-se, principalmente, pela elevação do conteúdo de gordura, proteína e lactose.

TABELA 3- Composição do leite em diferentes épocas do ano de uma propriedade localizada no norte do Rio Grande do Sul.

\begin{tabular}{lcccc}
\hline Estação do ano & Gordura (\%) & Proteína (\%) & Lactose (\%) & EST (\%) \\
\hline Verão & $3.71 \mathrm{~b}$ & $3.28 \mathrm{~b}$ & $4.41 \mathrm{a}$ & $12.39 \mathrm{~b}$ \\
Outono & $4.16 \mathrm{a}$ & $3.49 \mathrm{a}$ & $4.31 \mathrm{~b}$ & $13.03 \mathrm{a}$ \\
Inverno & $3.68 \mathrm{~b}$ & $3.55 \mathrm{a}$ & $4.39 \mathrm{a}$ & $12.65 \mathrm{a}$ \\
Primavera & $3.53 \mathrm{~b}$ & $3.39 \mathrm{~b}$ & $4.43 \mathrm{a}$ & $12.12 \mathrm{~b}$ \\
Média & 3.77 & 3.43 & 4.38 & 12.54 \\
CV & 7.74 & 2.97 & 1.18 & 3.40 \\
P $>f$ & 0.0112 & 0.0018 & 0.0043 & 0.0142
\end{tabular}

Médias seguidas de letras distintas, nas colunas, diferem pelo teste Scott Knott $(P<0,05)$.

Não foi observada influência das estações sobre o preço pago pelo litro de leite (Tabela 4); o preço médio pago ao produtor foi de $R \$ 1,09$. Segundo os dados do IBGE (2018), em relação ao preço médio do litro de leite entre os anos de 2013 a 2018, observam-se oscilações no preço médio pago ao produtor nos seis anos consecutivos. Entretanto, de 2013 a 2018 obteve-se um aumento de 0,52 centavos por litro e no terceiro semestre de 2018 o preço pago ao produtor foi $19,6 \%$ maior que o valor do trimestre anterior.

De acordo com o levantamento do CEPEA (2019), o valor do litro do leite pago ao produtor entre os anos de 2013 a 2016 teve um crescimento considerado no Brasil, entretanto, o mesmo decaiu em 2015 e 2017 e voltou a crescer no ano de 2016 e 2018. O cenário não foi diferente no estado do Rio Grande do Sul. 
Segundo a EMBRAPA (2018) a variação do preço do litro do leite ocorreu pelas transações lácteas no mercado internacional, nas quais, o leite importado tornou-se mais barato para o consumidor, do que o produzido internamente. Entretanto, no ano de 2015 houve queda de 1,5\% da oferta de leite, no ano seguinte a oferta continuou a decrescer, resultando em queda de $2,8 \%$, entre os anos de 2014 e 2016 totalizou queda de oferta de 4,27\%, além disso, as condições econômicas dos consumidores podem interferir na demanda por produtos lácteos (CONAB, 2019).

TABELA 4- Preço do litro do leite e produção média em diferentes épocas do ano de uma propriedade localizada no norte do Rio Grande do Sul.

\begin{tabular}{lcc}
\hline Estação do ano & Preço $(\mathrm{R} \$)$ & Produção média \\
\hline Verão & 1,02 & $9.003 \mathrm{a}$ \\
Outono & 1,06 & $7.928 \mathrm{~b}$ \\
Inverno & 1,16 & $9.337 \mathrm{a}$ \\
Primavera & 1,10 & $1.0023 \mathrm{a}$ \\
Média & 1,09 & 9.073 \\
CV & 11,60 & 9.68 \\
$\mathrm{P}>f$ & 0.3501 & 0.0071 \\
\hline
\end{tabular}

Médias seguidas de letras distintas, nas colunas, diferem pelo teste Scott Knott $(P<0,05)$.

Quanto a qualidade do leite, avaliada pelos parâmetros CCS e CPP (Tabela 5) não houveram diferenças significativas $(P>0,05)$ em função da época de produção; e valores de CCS no inverno e na primavera ficaram dentro dos parâmetros estabelecidos pela Instrução Normativa vigente no período estudado (IN 62/2011), enquanto que a CPP somente no verão ficou acima dos parâmetros estabelecidos pela IN 62/2011 (BRASIL, 2011). Roma Júnior et al. (2009), observaram aumento significativo de CCS no verão e diminuição de CPP no outono; além disso, Milani et al. (2016), determinaram aumento de CPP no inverno e CCS no verão.

O aumento da CCS no leite ocorre pela infecção na glândula mamária, fazendo com que as células de defesa migrem do sangue para o local de infecção (JAMAS et al., 2018). A mastite acarreta grandes perdas econômicas para o produtor, como alteração na qualidade do leite, descarte, redução da produção, diminuição dos níveis de caseína, lactose, gordura, potássio, cálcio, além da elevação dos teores de cloro, sódio, da proteína do soro e do pH do leite (DEMEU et al., 2016; COSTA et al., 2017).

Segundo SANTOS e FONSECA (2019), vacas com presença de mastite apresentam diminuição nos componentes do leite, entretanto, as alterações nos componentes irão depender do agente causador e da intensidade da inflamação da glândula mamária, além disso, a elevação de CCS fará com que aumente a ação das enzimas proteolíticas e outras proteases, estas irão degradar a caseína e assim, ocorrer à liberação de peptídeos, causando sabor amargo e odor no leite. 
TABELA 5- Qualidade do leite em diferentes épocas do ano de uma propriedade localizada no norte do Rio Grande do Sul.

\begin{tabular}{lcc}
\hline Estação do ano & CCS $(\times 1000 \mathrm{cel} / \mathrm{mL})$ & $\mathrm{CPP}(\mathrm{x} 1000 \mathrm{UFC} / \mathrm{mL})$ \\
\hline Verão & 992,85 & 347,60 \\
Outono & 635,32 & 267,59 \\
Inverno & 484,28 & 123,50 \\
Primavera & 415,51 & 181,05 \\
Média & 631,99 & 229,94 \\
CV & 74.83 & 68.19 \\
$\mathrm{P}>\mathrm{f}$ & 0.1943 & 0.1127
\end{tabular}

Médias seguidas de letras distintas, nas colunas, diferem pelo teste Scott Knott $(\mathrm{P}<0,05)$.

\section{CONCLUSÃO}

As estações do ano influenciaram na composição e produção do leite, mas não influenciaram na qualidade e preço pago pelo litro do leite. Por fim, enfatiza-se que há necessidade de mais estudos na área, visto que a produção e composição do leite variam ao longo dos anos, principalmente em sistemas a base de pastagens.

\section{REFERÊNCIAS}

ALVARES, C.A.; STAPE, J.L.; SENTELHAS, P.C.; ALVES, J.L.M.G.; SPAROVEK, P.C. Köppen's climate classification map for Brazil. Meteorologische Zeitschrift, v. 22, n. 6, p. 711-728, 2013. Disponível em:< https://doi.org/10.1127/09412948/2013/0507>. doi: 10.1127/0941-2948/2013/0507.

BRASIL. Ministério da Agricultura, Pecuária e Abastecimento. Instrução Normativa n. 62, de 29 de dezembro de 2011. Regulamento técnico de produção, identidade e qualidade do leite tipo $\mathrm{A}$, o regulamento de identidade e qualidade de leite cru refrigerado, 0 regulamento técnico de identidade e qualidade de leite pasteurizado e o regulamento técnico da coleta de leite cru refrigerado e seu transporte a granel. Diário Oficial da República Federativa do Brasil, Brasília, DF, 30/dez/2011. Disponível em:< https://www.apcbrh.com.br/files/IN62.pdf>.

CARVALHO G.R.; ROCHA D.T.; CARNEIRO, A.V.; Indicadores leite e derivados. EMBRAPA. Ano 9, n. 83 Outubro/2018. Disponível em: $<$ https://www.embrapa.br/busca-de-publicacoes/-/publicacao/1104350/indicadoresleite-e-derivados-v-10-n-86-2019 >

CEPEA- Centro de Estudos Avançados em Economia Aplicada. Leite ao produtor CEPEA/ESALQ (R\$/litro). Disponível em:< https://www.cepea.esalq.usp.br/br/indicador/ovos.aspx>.

CONAB- Companhia Nacional de Abastecimento. Brasil é responsável por cerca de $7 \%$ do leite produzido no mundo. Disponível em:<https://www.conab.gov.br/ultimas-noticias/2634-brasil-e-responsavel-porcercade-7-do-leite-produzido-no-mundo>.

COSTA, H.H.; MOLINA, L.R.; LAGE, C.F.A.; MALACCO, V.M.R.; FACURY FILHO, E.J.; CARVALHO, A.U. Estimativa das perdas de produção leiteira em vacas mestiças Holandês x Zebu com mastite subclínica baseada em duas metodologias de análise. Revista Brasileira de Medicina Veterinária e Zootecnia. v. 69, p. 579- 
86. 2017.Disponível em: <http://dx.doi.org/10.1590/1678-4162-9019>. doi: 10.1590/1678-4162-9019.

DEMEU, F. A.; LOPES, M.A.; COSTA, G.M.; ROCHA, C.M.B.M.; SANTOS, G. Efeito da produtividade diária de leite no impacto econômico da mastite em rebanhos bovinos. Revista Boletim de Indústria Animal. v. 73, p. 53-61, 2016. Disponível em:< https://doi.org/10.17523/bia.v73n1p53>. doi: 10.17523/bia.v73n1p53.

DIAS, M.B.C.; LEÃO, K.M.; CARMO, R.M.; SILVA, M.A.P.; NICOLAU, E.S.; MARQUES, T.C. Milk composition and blood metabolic profile from holstein cows at different calving orders and lactation stages. Acta Scientiarum Animal Sciences, v. 39, n. 3, p. 315-321, 2017. Disponível em: < http://dx.doi.org/10.4025/actascianimsci.v39i3.34807 >. doi: 10.4025/actascianimsci.v39i3.34807.

DIAS, M.; ASSIS, A.C.F.; NASCIMENTO, V.A.; SAENZ, E.A.C.; LIMA, L.A. Sazonalidade dos componentes do leite e o programa de pagamento por qualidade. Enciclopédia Biosfera, v. 11, n. 21, p.17-12, 2015. Disponível em :< https://www.conhecer.org.br/enciclop/2015b/agrarias/sazonalidade\%20dos\%20comp onentes.pdf $>$.

EMBRAPA- Empresa Brasileira de Pesquisa Agropecuária. Indicadores, tendências e oportunidades para quem vive no setor leiteiro. Anuário leite 2018. Disponível em:<https://www.embrapa.br/busca-de-publicacoes//publicacao/1094149/anuario-leite2018-indicadores-tendencias-e-oportunidadespara-quem-vive-no-setor-leiteiro>.

FÉRRER, M. T.; FRANQUE, A.S.S.; MELO SANTORO, K.R. Variabilidade espacial da composição do leite cru refrigerado no estado de Alagoas e na mesorregião do Agreste Pernambucano. Arquivo Brasileiro de Medicina Veterinária e Zootecnia, v. 70, n. 6, p. 1925-1934, 2018.Disponível em: <http://dx.doi.org/10.1590/1678-41629509 >. doi: 10.1590/1678-4162-9509.

FERREIRA, D.F. SISVAR: A guide for its bootstrap procedures in multiple comparasons. Ciência e Agrotecnolgia, Lavras, v. 38, n. 2, p. 109-112, 2014. Disponível em:< https://doi.org/10.1590/S1413-70542014000200001>. Doi: 10.1590/S1413-70542014000200001.

HAYGERT-VELHO, I.M.P; CONCEIÇÃO, G.M; COSMAM, L.C; ALESSIO, D.R.M; BUSANELLO, M.; et al. Multivariate analysis relating milk production, milk composition, and seasons of the year. Academia Brasileira de Ciências, v. 90, n. 4, p. 3839-3852, 2018. Disponível em:<https://doi.org/10.1590/00013765201820180345>. doi: 10.1590/0001-3765201820180345.

IBGE- Instituto Brasileiro de Geografia e Estatística. Estatística da Produção Agropecuária. Aquisição e Industrialização de Leite - Brasil. Disponível em:<https://biblioteca.ibge.gov.br/visualizacao/periodicos/2380/epp_2018_2tri.pdf>.

JAMAS, L.; SALINA, A.; ROSSI, R.; MENOZZI, B.D.; LANGONI, H. Parâmetros de qualidade do leite bovino em propriedades de agricultura familiar. Pesquisa Veterinária Brasileira. v. 38, n. 4, p. 573-578, abril. 2018. Disponível em:< 10.1590/1678-5150-PVB-5372>. doi: 10.1590/1678-5150-PVB-5372. 
LAMPUGNANI, C.; PERIN, A.P.; ZIECH, R.E.; JÚNIOR, O.A.C.; MONTANHINI, M.T.M.; BERSOT, L.S. Qualidade do leite cru refrigerado e características da produção leiteira na mesorregião oeste paranaense, brasil. Revista do Instituto de Laticínios Cândido Tostes. Juiz de Fora. v. 73, n. 1, p. 19-26, jan/mar. 2018. Disponível em: <https://doi.org/10.14295/2238-6416.v73i1.650>. doi: 10.14295/2238-6416.v73i1.650.

LIMA, L.S. Modelo de Sistema de Gestão da Qualidade para Propriedades Rurais Leiteiras. $2004 . \quad$ Disponível em: <https://repositorio.ufscar.br/bitstream/handle/ufscar/3724/DissLSL.pdf?sequence=1 $>$.

MILANI, M.P.; VARGAS, D.P.; MELLO, R.O.; NÖRNBERG, M.F.B.; NÖRNBERG, J.L. Qualidade do leite em diferentes sistemas de produção, ano e estação climática. Revista Brasileira de Ciência Veterinária, v. 23, p. 3-4, 2016. Disponível em: <http://doi.editoracubo.com.br/10.4322/rbcv.2016.058>. doi.: 10.4322/rbcv.2016.058.

NORONHA, J.F.; LIMA JÚNIOR, A.C.S.; Tecnologia de gestão na propriedade leiteira. Tecnologia e gestão na atividade leiteira. Juiz de Fora: Embrapa Gado de Leite. p. 41-55, 2005. Disponível em:< http://www.sidalc.net/cgibin/wxis.exe/? IsisScript=agrinpa. $x i s \&$ method=post\&formato=2\&cantidad $=1$ \&expresio $\mathrm{n}=\mathrm{mfn}=028105>$.

PEIXOTO, A.L.; SILVA, M.A.P.; MORAIS, L.A.; SILVA, F.R.; CARMO, R.M.C.; LAGE, M.E. Influência do tipo de ordenha e do armazenamento do leite sobre a composição química, contagem de células somáticas e contagem bacteriana total. Revista Institucional de Laticínios Cândido Tostes. Juiz de Fora, v. 71, n. 1, p. 10-18, jan/mar. 2016. Disponível em: <https://doi.org/10.14295/22386416.v71i1.460>. doi: 10.14295/2238-6416.v71i1.460.

ROMA JÚNIOR, L.C.; MONTOYA, J.F.G.; MARTINS, T.T.; CASSOLI, L.D.; MACHADO, P. F. Sazonalidade do teor de proteína e outros componentes do leite e sua relação com programa de pagamento por qualidade. Arquivo Brasileiro de Medicina Veterinária e Zootecnia, v. 61, n. 6, p. 1411, 2009. Disponível em: <https://doi.org/10.1590/S0102-09352009000600022>.doi:10.1590/S0102 09352009000600022.

SANTOS, M. V.; FONSECA, L. F. L. Controle da Mastite e Qualidade do LeiteDesafios e Soluções. 1ำ ed. Pirassununga-SP. Copuright, p. 22-23 2019.

VILELA, D.; RESENDE, J.C.; LEITE, J.B.; ALVES, E. A evolução do leite no Brasil em cinco décadas. Revista de Política Agrícola, n. 1, p. 5-24, 2017. Disponível em: $<$ https://seer.sede.embrapa.br/index.php/RPA/article/view/1243/1037>. 